University of Nebraska - Lincoln

DigitalCommons@University of Nebraska - Lincoln

Faculty Publications, Department of Psychology

Psychology, Department of

July 2005

\title{
Acculturation Status and Sexuality Among Female Cuban American College Students
}

Marcela Raffaelli

University of Nebraska-Lincoln, mraffaelli1@unl.edu

Byron L. Zamboanga

Smith College, bzamboan@email.smith.edu

Gustavo Carlo

University of Nebraska-Lincoln, carlog@missouri.edu

Follow this and additional works at: https://digitalcommons.unl.edu/psychfacpub

Part of the Psychiatry and Psychology Commons

Raffaelli, Marcela; Zamboanga, Byron L.; and Carlo, Gustavo, "Acculturation Status and Sexuality Among Female Cuban American College Students" (2005). Faculty Publications, Department of Psychology. 89. https://digitalcommons.unl.edu/psychfacpub/89

This Article is brought to you for free and open access by the Psychology, Department of at DigitalCommons@University of Nebraska - Lincoln. It has been accepted for inclusion in Faculty Publications, Department of Psychology by an authorized administrator of DigitalCommons@University of Nebraska - Lincoln. 


\title{
Acculturation Status and Sexuality Among Female Cuban American College Students
}

\author{
Marcela Raffaelli, PhD; Byron L. Zamboanga, PhD; Gustavo Carlo, PhD
}

\begin{abstract}
The authors examined relations among different measures of acculturation, and between acculturation and sexual behavior, in a sample of female Cuban American college students ( $n=61, M$ age $=18.4$ years $)$ who completed self-report surveys. In the first set of analyses, weak to moderate associations emerged among 4 measures of acculturation (birthplace, childhood language use, current language use, and ethnic identity), suggesting that inconsistent findings from prior research may have resulted from measurement limitations. In multivariate analyses, the authors examined predictors of sexual behavior and found that 1 aspect of acculturation (higher levels of ethnic identity) and background characteristics (being older and less religious) were associated with voluntary sexual intercourse. Moreover, higher levels on a sexual risk composite were associated with being born in the United States, more ethnically identified, older, and less religious. These analyses highlight the need for specificity in assessing acculturation in a college student population and support the need to examine cultural factors directly in sexuality research.
\end{abstract}

Key Words: acculturation, sexuality, women, Cuban Americans

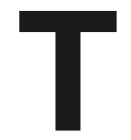
he sexual health of college students in the United States has been an area of increasing concern in recent years. ${ }^{1}$ Sexual risk behaviors that put individuals at risk of sexually transmitted infections and unplanned pregnancies include inconsistent condom use, sex with multiple partners, early sexual debut, and forced sexual intercourse. Inconsistent condom use puts individuals at direct risk of pregnancy or exposure to sexually transmitted infections, ${ }^{2}$ particularly when combined with multiple sexual relationships. ${ }^{3,4}$ Early initiation of sexual activity is associated with lower condom and contraceptive use, ${ }^{5}$ an increase in the number of sex partners, ${ }^{6,7}$ and a higher inci-

Marcela Raffaelli is a professor of psychology and ethnic studies and Gustavo Carlo is a professor of psychology, both with the University of Nebraska-Lincoln. Byron L. Zamboanga is an assistant professor of psychology at Smith College, MA. dence of sexually transmitted infections. ${ }^{6}$ Finally, researchers have linked forced or coercive sexual intercourse to risk of HIV/AIDS among women. ${ }^{8,9}$ These risks affect all demographic groups, but recent research suggests that members of certain groups are at heightened risk of unplanned pregnancies and sexually transmitted infections. Current concern centers on the sexual health of Latinas (women of Hispanic or Latin American origin or descent living in the United States).

Considerable evidence suggests that adolescent and young adult Latinas are in need of sexual health interventions. In 1999, Latinas had the highest teen birth rate in the United States-93.1 per 1,000 (nearly twice the national rate). ${ }^{10}$ Latinas represent $9.9 \%$ of the over- 21 female population in the United States ${ }^{11}$ but account for $19.6 \%$ of cumulative female AIDS cases. ${ }^{12}$ According to studies of general populations of adults ${ }^{13}$ teens attending traditional ${ }^{14}$ and alternative ${ }^{15}$ high schools, and college students, ${ }^{1}$ Latinas are more likely to engage in unprotected intercourse than are women from other ethnic groups. For example, in a national survey of girls aged 15 to 19 years, $42 \%$ of Latina girls did not use any method of contraception at first intercourse, compared with $24 \%$ of non-Latina girls in the same age range. ${ }^{10}$ Moreover, sexually active Latina college students are less likely to use condoms than are their peers from other ethnic groups. ${ }^{1}$ Researchers know less about other forms of sexual risk behavior among Latinas, and the factors linked to overall levels of sexual risk in this population remain unclear. ${ }^{16}$

One factor that researchers have identified as an important modifier of sexual behavior among Latina populations is acculturation. ${ }^{17,18}$ Acculturation is the process of psychological and behavioral adaptation that occurs when 2 cultures come into contact, as happens when immigrants arrive in a new country or 1 group is colonized by another. ${ }^{19,20}$ As individuals acculturate, they typically take on behaviors (eg, lan- 
guage, forms of dress) and attitudes (eg, values, beliefs) of the dominant culture. As Latinas become more acculturated to the United States, some aspects of their sexual behavior become more Americanized. Specifically acculturated Latinas are more likely than are less acculturated Latinas to engage in nonmarital sexual activity and have multiple partners. ${ }^{18,21-25}$ For example, in 1 study, $41 \%$ of third-generation Mexican American women reported that they had engaged in sexual intercourse, compared with $18.5 \%$ of first-generation Mexican American women. ${ }^{23}$ Among never-married Hispanic women aged 15 to 24 years, higher levels of acculturation (indexed by use of English vs Spanish language) significantly predicted young women's sexual activity during the past year. ${ }^{24}$ At the same time, condom use is rare even among highly acculturated Latinas. ${ }^{18,24,25}$ For example, Englishspeaking Latinas were only slightly less likely than Spanishspeaking Latinas to say they never used condoms (71\% vs $79 \%$ ); in contrast, only $53 \%$ of non-Hispanic white women said they never used condoms. ${ }^{17}$ Thus, acculturation appears to increase the likelihood that Latinas will engage in sexual activity with multiple partners, but not the probability that they will use condoms.

Sexuality research often views acculturation as unidimensional and global, with immigrants moving from being "unacculturated" to becoming "acculturated" to the mainstream values of the host country. In keeping with this view, most empirical studies of Latina sexual behavior use language as a measure of acculturation ${ }^{17,18,24,25}$ (1 used generation of immigration ${ }^{23}$ and another birthplace $\left.{ }^{21}\right)$. However, these measures may not fully capture the complexities of the acculturative process. ${ }^{26-29}$ Generational status, language use, and birthplace can be seen as measures of "distance" from the home country but provide limited information with respect to psychological aspects of cultural adaptation. ${ }^{16,30}$ Therefore, to understand the influence of acculturative processes on sexual behavior, it may be useful to examine subjective dimensions of acculturation.

An aspect of psychological functioning that researchers have linked to behavior and values is ethnic identity, the personal sense of oneself as a member of a particular ethnic group. ${ }^{31}$ Researchers define and assess ethnic identity in various ways, but it typically encompasses involvement in cultural activities and feelings regarding ethnic group membership. ${ }^{32}$ Ethnic identity does not appear to be related in any consistent manner to demographic measures of acculturation such as generational status or birthplace. ${ }^{33}$ For example, research with multiple ethnic groups reveals no consistent pattern of relations between ethnic identity and generational status, ${ }^{31}$ and research with Latina populations suggests that ethnic identity remains strong regardless of demographic factors. ${ }^{34}$ These findings suggest that demographic indicators of acculturation may be inadequate measures of cultural values that are likely to be more relevant predictors of sexual behavior. This would be particularly true of college students, who may be highly acculturated based on language use and generation yet differ in their adherence to cultural norms, strength of ethnic identification, and other psychological dimensions. ${ }^{35}$

The current analysis builds on prior research examining acculturation and sexual behavior among Latinas in 2 ways: (1) In an effort to understand how different aspects of acculturation operate on sexual behaviors in a college sample, we examined interrelations among different measures of acculturation and (2) we examined linkages between these indices of acculturation and sexual behavior. The sample consisted of female Cuban American college students. By limiting the sample in this way, we addressed a limitation in prior research, which too often ignored the diversity of the Latina population.

Despite sharing a common heritage of European colonization and geographic proximity, there are significant differences between US Latino subgroups in terms of timing of arrival, demographic characteristics, and pre- and postimmigration experiences. ${ }^{16,36}$ Cuban Americans differ quite markedly from other US Latino groups in their immigration experiences. ${ }^{37}$ Since 1959, immigrants from the island have arrived in periodic waves as well as individually or in small groups. The first arrivals, who left Cuba when Fidel Castro came to power in 1959 , were primarily professionals and entrepreneurs to whom the United States granted official refugee status and gave resettlement assistance. Later immigrants were more socioeconomically diverse and settled in southern Florida, creating a politically active and vibrant ethnic enclave that provided support for maintaining cultural traditions. Overall, Cubans (especially those who arrived in the United States before the 1970s) have prospered economically compared with immigrants from other Latin American countries: Cuban Americans are more highly educated, less likely to be poor, and more likely to own their own homes than other Latino groups. ${ }^{38}$

Differences among Latino subgroups extend to sexual behavior, as differential rates of HIV/AIDS ${ }^{39}$ and teen pregnancy ${ }^{10}$ among Latino subgroups show. Thus, to obtain a more complete picture of risk and protective factors influencing the sexual behavior of Latinas, different subgroups must be considered separately. ${ }^{40}$ In the current analysis, we addressed 2 research questions in a sample of female Cuban American college students: (1) What are the interrelations among different indicators of acculturation (ie, language, birthplace, and ethnic identity)? and (2) What are the relations between these different acculturation indicators and sexual behavior?

Because research links age, parental education, and religiosity to sexual behavior, ${ }^{18,21,23,40}$ we also considered these background variables in the current analysis.

\section{METHOD}

\section{Participants and Procedures}

The sample consisted of 61 young women of Cuban origin or descent $(M$ age $=18.4, S D=1.2$, range 17-23) who were part of a larger multiethnic sample $(N=269)$ from a state university in southern Florida. The Institutional Review 
Boards at the University of Nebraska-Lincoln and Florida International University approved the research. Students who were enrolled in introductory psychology and other psychology courses volunteered to participate; thus, this was a convenience sample, and we did not know the number of students eligible to participate. After providing written informed consent, participants completed anonymous selfreport questionnaires in small groups. Students received a written debriefing form and credit for completing the study.

\section{Measures}

Respondents provided demographic information and completed a set of structured measures, including those we examined in the current study. Predictor variables included 3 background variables and 4 indicators of acculturation identified in prior research. Two aspects of sexual behavior served as the dependent variables.

\section{Background Variables}

Participants reported on their age, each parent's level of education, and religiousness. They reported age in years $(M=18.4, S D=1.2)$. We computed parental education as an average of maternal and paternal education $(r=.46, p<$ $.01)$ rated on a 7-point scale $(1=$ elementary or junior high school; 4 = graduated from 2-year college or technical school; 7 = professional or graduate school; $M=3.13, S D$ $=1.4$ ). We computed religiousness as the average of 2 items (importance of religion and frequency of church attendance; $r=.69, p<.01)$ on a 5-point Likert-type scale (from $1=$ not at all important [importance] or never go to church [attendance] to $5=$ very important or more than once a week). A higher score indicated a higher level of religiousness $(M=3.31, S D=1.0)$.

\section{Acculturation}

We examined 4 aspects of acculturation. We coded respondent birthplace as either non-US (18\%) or US (82\%). (Over four fifths [82\%] of the US-born resp-ondents had 2 non-US-born parents, so it was not possible to examine generation status in the US in detail.) We assessed childhood and current language use by using a 5-point scale $(1=$ Spanish only, $3=$ both the same, $5=$ English only). We assessed childhood language with a single item ("What language did you speak as a child?"; $M=2.21, S D=1.1$ ) and current language with 5 items measuring language use in different situations (read, speak, speak at home, think in, speak with friends; $M=3.76, S D=0.6$ ). The current language items were similar to those on the Short Acculturation Scale for Hispanic Youth ${ }^{41}$ and yielded a Cronbach's alpha coefficient of .80 . We assessed ethnic identity with a 9-item version of the ethnic identity subscale of the MultiEthnic Identity Measure ${ }^{32}$ (eg, "I have a strong sense of belonging to my own ethnic group") rated on a 4-point Likert-type scale $(1=$ strongly disagree to $4=$ strongly agree). We computed an overall score by averaging the 9 items (Cronbach $\alpha=.84$ ); a higher score indicated a higher level of ethnic identity $(M=2.99, S D=0.6)$.

\section{Sexual Behavior}

Respondents indicated whether they had ever had voluntary or involuntary sexual intercourse, and those with sexual experience completed a set of sexual behavior items. Over half of the sample (57\%) reported voluntary sex; 6 of these women also reported involuntary sex (no woman reported only involuntary sex). The average age at first intercourse was 16.8 years $(S D=1.6)$, and lifetime number of sexual partners was $3.03(S D=2.8)$. Sexual risk is multidimensional, reflecting a number of different behaviors, some voluntary and some non-voluntary. Therefore, we computed a sexual risk score for each participant by assigning 1 point for each of the following: ever had voluntary sex, voluntary sex before age 16,4 or more lifetime sex partners, lifetime condom use under $75 \%$ of intercourse acts, ever forced to have sex. The sexual risk score $(M=1.02, S D=1.3)$ ranged from 0 (participants who had never had sex) to 5 (participants reporting all 5 risk factors).

\section{Data Analytic Approach}

We conducted data analyses using SPSS (SPSS, Inc., Chicago, IL) for Windows, version 11.5. Bivariate analyses involved computing Pearson product moment correlation coefficients; in cases where 1 variable was dichotomous as opposed to continuous (eg, birthplace, ever had sex), SPSS automatically substituted the Point Biserial Correlation. ${ }^{42}$ To examine the independent relationships between different aspects of acculturation and sexual behavior, we computed logistic and linear regression models. In these models, we entered background variables (age, parent education, and religiousness) on the first step and acculturation variables (birthplace, childhood language, current language, and ethnic identity) on the second step. We used logistic regression analysis to predict lifetime sexual activity (a dichotomous outcome) and linear regression analysis to predict scores on the sexual risk composite (a continuous outcome). The alpha level was set at .05; however, given the small sample size, we also described trends $(p<.10)$ for informational purposes.

\section{RESULTS}

Table 1 shows bivariate associations among study variables. Looking first at the relationships between background characteristics and the study variables, age was significantly associated with birthplace (older women were more likely to be non-US born) and sexual behavior (older women were more likely to report ever having sex and engaged in higher levels of sexual risk compared with younger women). Parent education was not significantly associated with any other variable. Religiousness was significantly associated with ethnic identity (positively) and sexual behavior (negatively).

\section{Interrelations Among Indicators of Acculturation}

The first research question focused on the interrelations among different indicators of acculturation. Birthplace was 
TABLE 1. Correlations Among Study Variables

\begin{tabular}{|c|c|c|c|c|c|c|c|c|c|}
\hline Variable & 1 & 2 & 3 & 4 & 5 & 6 & 7 & 8 & 9 \\
\hline 1. Age & - & -.13 & -.03 & $.25 *$ & -.08 & .03 & -.19 & $.29 *$ & $.30 *$ \\
\hline 2. Parent education & & - & .11 & -.11 & .19 & .23 & -.18 & .02 & .00 \\
\hline 3. Religiousness & & & - & -.14 & -.03 & $-.25+$ & $.41 * * *$ & $-.28 *$ & $-.25+$ \\
\hline 4. Birthplace $\dagger$ & & & & - & -.17 & $-.28^{*}$ & .16 & .04 & -.10 \\
\hline 5. Childhood language $\ddagger$ & & & & & - & $.38 * *$ & $-.24+$ & .04 & .01 \\
\hline 6. Current language $\$$ & & & & & & - & $-.38 * *$ & .12 & .13 \\
\hline 7. Ethnic identity & & & & & & & - & .12 & .02 \\
\hline 8. Ever had sex§ & & & & & & & & - & - \\
\hline 9. Sexual risk & & & & & & & & & - \\
\hline
\end{tabular}

Note. $N$ s range from $50-57$ because of missing data on some variables.

$\dagger$ Birthplace coded as $0=$ US, $1=$ non-US.

$\ddagger$ Higher scores indicate more English language use, lower scores indicate more Spanish language use.

$\S$ Coded as $0=n o, 1=$ yes (part of Sexual Risk Score).

$+p<.10 . * p<.05 . * * p<.01 . * * * p<.001$, two-tailed.

significantly related to current language use (respondents born outside the United States used more Spanish), and current and childhood language use were positively related with each other; however, birthplace and childhood language were not significantly associated. Respondents with higher levels of ethnic identity reported using more Spanish currently than those with lower levels of ethnic identity. Ethnic identity was not significantly associated with childhood language or birthplace.

\section{Relationships Between Acculturation and Sexual Behavior}

In bivariate analyses, sexual activity and level of sexual risk were associated positively with age and negatively with religiousness, but not with any of the acculturation variables. We conducted 2 multivariate analyses to examine the unique associations between acculturation indicators and sexual behavior.

Table 2 presents the results of the logistic regression examining predictors of voluntary sexual intercourse. The top portion of the table displays classification statistics for the 2 blocks of predictors (background variables and acculturation measures). The classification analysis revealed that background variables significantly predicted sexual intercourse. When we added acculturation measures on the second step, there was a marginally significant increase $(p<$ $.10)$ in the proportion of respondents correctly classified. Statistics for individual predictors (bottom half of the table) show that lifetime sexual activity was significantly associated with being older, less religious, and more ethnically identified.

We conducted linear multiple regression analysis to examine predictors of the composite sexual risk scores (see Table 3). Background variables entered at the first step significantly predicted sexual risk, with age and religiousness emerging as significant individual predictors and accounting for $15 \%$ of the systematic variance. At the second step, acculturation variables accounted for an additional $14 \%$ of the systematic variance, although this was a nonsignificant improvement $(p<.10)$ in the model. The final model was significant: adjusted $R^{2}=.19, F(7,50)=2.93, p<.02$. Two of the background variables and 2 of the acculturation variables emerged as significant individual predictors of overall level of sexual risk. Age and ethnic identity were related positively, and religiousness and birthplace negatively, to sexual risk scores. Thus, among female Cuban American college students, higher levels of sexual risk were associated with

TABLE 2. Logistic Regression Predicting Voluntary Sexual Intercourse From Background Variables and Acculturation Measures

\begin{tabular}{|c|c|c|c|}
\hline Classification analysis & & $\chi^{2}$ & $\begin{array}{c}\% \\
\text { correct }\end{array}$ \\
\hline Demographics & & $10.84 *$ & 69.2 \\
\hline Acculturation status & & $8.89+$ & 78.85 \\
\hline Model statistic & $\beta$ & $S E$ & $\begin{array}{c}\text { Odds ratio } \\
{[\operatorname{Exp}(\mathrm{b})]}\end{array}$ \\
\hline \multicolumn{4}{|l|}{ Background variable } \\
\hline Age & $1.27 *$ & .51 & 3.57 \\
\hline Parent education & .49 & .32 & 1.64 \\
\hline Religiousness & $-1.37 * *$ & .48 & .25 \\
\hline \multicolumn{4}{|l|}{ Acculturation measure } \\
\hline Birthplace & -1.43 & 1.17 & .24 \\
\hline Childhood language & .21 & .37 & 1.23 \\
\hline Current language & .10 & .65 & 1.11 \\
\hline Ethnic identity & $2.47 * *$ & 1.02 & 11.79 \\
\hline
\end{tabular}

Note. Table shows final model statistics. All betas are standardized. Significance of individual predictor coefficients (based on the Wald statistic).

$+p<.10 .{ }^{*} p<.05$. ** $p<.01$. 
TABLE 3. Linear Regression Analysis Predicting Sexual Risk Scores From Background Variables and Acculturation Measures

\begin{tabular}{|c|c|c|c|c|c|c|c|}
\hline Step & Variable & $\Delta R^{2}$ & $R^{2}$ & $d f$ & $\begin{array}{c}F \text { for } \\
\Delta R^{2}\end{array}$ & $\begin{array}{c}\beta \\
\text { (1st step) }\end{array}$ & $\begin{array}{c}\beta \\
\text { (2nd step) }\end{array}$ \\
\hline \multirow[t]{4}{*}{1} & Background variable & .15 & .15 & 3,54 & $3.25^{*}$ & & \\
\hline & Age & & & & & $.29 *$ & $.46^{* *}$ \\
\hline & Parent education & & & & & .07 & .13 \\
\hline & Religiousness & & & & & $-.26^{*}$ & $-.46 * *$ \\
\hline \multirow[t]{5}{*}{2} & Acculturation measure & .14 & .29 & 7,50 & $2.44+$ & & \\
\hline & Birthplace & & & & & & $-.34 *$ \\
\hline & Childhood language & & & & & & .03 \\
\hline & Current language & & & & & & .01 \\
\hline & Ethnic identity & & & & & & $.36^{*}$ \\
\hline
\end{tabular}

Note. All betas are standardized.

$+p<.10 . * p<.05$. $* * p<.01$.

being older, US-born, more ethnically identified, and less religious.

\section{COMMENT}

Researchers in past studies have not fully elucidated the impact of acculturation on sexual risk levels among ethnically diverse populations. In this study, we attempted to clarify the mixed findings in prior research by examining acculturation and sexual behavior in 1 specific Latino subgroup: female Cuban American college students. The findings are relevant to 2 areas of research that are currently the subject of attention and debate. The first involves how to measure acculturation, and the second involves the association between acculturation status and sexual behavior.

Researchers have conceptualized and assessed acculturation in a variety of ways in earlier studies. ${ }^{26,29}$ Thus, our first goal in this study was to examine interrelations among different measures of acculturation. Of the 6 correlations among the 4 different indicators of acculturation (birthplace, current language use, childhood language use, and ethnic identity), 3 were significant at the .05 level, none exceeded .38 , and the mean correlation was .27 . No consistent pattern of association emerged among these measures. For example, women who were born outside the United States reported higher levels of current Spanish use; however, childhood language was not linked to birthplace. Similarly, ethnic identity, which assesses a psychological aspect of acculturation (the degree to which individuals feel attached to their "native" culture), was associated with language use but not birthplace. This finding builds on recent research demonstrating differential associations between distinct aspects of acculturation, including generation of immigration, Spanish and English language use, and social networks. ${ }^{43}$ Findings of past research and the current findings indicate that different measures of acculturation share limited common variance and cannot be used interchangeably. This issue should be examined empirically; for example, scholars with access to large datasets containing multi- ple measures of acculturation can conduct more sophisticated analyses than our sample permitted (eg, confirmatory factor analysis).

Our second goal in this study was to investigate linkages between different measures of acculturation and the sexual behavior of female Cuban American college students. Somewhat different patterns of association between the various indicators of acculturation and sexual behavior emerged in different analyses. In bivariate analyses, only background variables of age and religiousness were significant correlates of lifetime sexual intercourse and sexual risk (indexed as a composite of different behaviors that increase the chances of exposure to sexually transmitted infections and the likelihood of unplanned pregnancy). In multivariate analyses, ethnic identity (for lifetime sex) and both ethnic identity and birthplace (for the sexual risk composite) emerged as independent significant predictors. The finding that older, less religious, and US-born Latinas were more likely to be sexually active and to engage in risky sexual behavior than were other Latinas is consistent with prior research. ${ }^{17,18,21,23-26}$

The association between a subjective aspect of acculturation (ethnic identity) and risky sexual behavior is a novel finding of the present study. Ethnic identity captures the degree to which individuals identify themselves as members of a particular group. ${ }^{33}$ Thus, having a strong sense of ethnic identity may reflect adherence to traditional cultural norms and values. In turn, traditional cultural norms regarding sexuality may be linked to sexual risk in Latina populations. A number of scholars have asserted that traditional Hispanic cultural norms related to sexuality include a dislike of condoms (perhaps linked to the beliefs of the majority Catholic religion or a reticence to discuss sexual topics that results in a preference for unobtrusive methods of birth control), as well as the notion that women should be ignorant of sex and submissive to men in sexual relationships. ${ }^{4-46}$ Despite some overlap between different measures of acculturation revealed in the first set of analyses, 
ethnic identity was an independent predictor of both lifetime sexual activity and cumulative sexual risk. This suggests that sexuality researchers should incorporate measures of subjective dimensions of cultural adaptation (eg, ethnic identity, culturally relevant values or attitudes ${ }^{29}$ ) into their studies rather than relying solely on measures such as birthplace, generation of immigration, or language use.

\section{Limitations}

There are a number of limitations that should be kept in mind when interpreting the findings from the present research. First, although 57\% of the sample reported engaging in sexual intercourse, overall levels of sexual risk were quite low, as might be expected in a college population. The limited variability in the sexual risk variable may have limited our ability to detect associations between acculturation indicators and sexual risk scores. Future research should examine these linkages in a sample at higher levels of sexual risk. Second, we did not select the participants randomly, and they may differ from the general population of college students. Third, despite assurances of anonymity, some participants may have been reluctant to report on their sexual behavior (although this is unlikely to have affected the relationships among the study variables). Finally, it is important to note that the findings cannot be generalized to non-college populations of Cuban American women. In 1990, fewer than 17\% of Cuban American women aged 25 years and older had completed 4 or more years of college. ${ }^{47}$ Additional research is needed to replicate the findings in different populations of Latinas.

The current study contributes to the scant literature on factors linked to sexuality among Cuban American college students. The preliminary nature of the study precludes any definitive conclusions or specific recommendations for promoting sexual health in this population. However, the findings suggest that sexual health interventions developed for the general college student population will not be optimally effective for Latinas because such programs are unlikely to address factors linked to sexual risk behavior in this population. Interventions for Latinas may need to consider immigration-related experiences and culturally relevant psychological dimensions, including ethnic identity. The need for such tailored programs will become increasingly acute in the near future because the Latina college student population is expected to increase dramatically in the next few decades. The US Department of Health and Human Services estimated that, within 50 years, nearly one third of the population under the age of 19 years in the United States will be of Hispanic origin or descent. ${ }^{48}$ Thus information about factors linked to the sexual well-being of Latina college students will be urgently needed for program development.

\section{ACKNOWLEDGMENT}

Grants to Gustavo Carlo and Marcela Raffaelli from the Institute for Ethnic Studies, the Gallup Research Center, and the University of Nebraska Research Council supported this study. The authors appreciate the assistance of Clarissa Bendezu, Deborah Laible, Kathryn Meyer, and Ellen Wilson. They also extend their deepest thanks to Ervin Briones for his valuable contribution to this project.

\section{NOTE}

For comments and further information, please address correspondence to Marcela Raffaelli, University of Nebraska-Lincoln, Department of Psychology and Institute for Ethnic Studies, 238 Burnett Hall, Lincoln, NE 68588-0308 (e-mail: mraffaelli1@ unl.edu).

\section{REFERENCES}

1. Centers for Disease Control and Prevention. National College Health Risk Behavior Survey-United States, 1995. MMWR. 1997;46(SS-6):1-57.

2. Lewis JE, Malow RM. HIV/AIDS risks in heterosexual college students. J Am Coll Health. 1997;45:147-159.

3. Corbin WR, Fromme K. Alcohol use and serial monogamy as risks for sexually transmitted diseases in young adults. Health Psychol. 2002;21:229-236.

4. MacNair-Semands RR, Simono RB. College student risk behaviors: implications for the HIV-AIDS pandemic. J Coll Stud Dev. 1996;37:574-583.

5. Manlove J, Terry E. Trends in sexual activity and contraceptive use among teens. Child Trends: Research Brief, 2000-03. Available at: http://www.childtrends.org. Accessed December 16, 2002.

6. Greenberg J, Magder L, Aral S. Age at first coitus: a marker for risky sexual behavior in women. Sex Transm Dis. 1992;19:331-334.

7. Miller BC, Christopherson CR, King PK. Sexual behavior in adolescence. In: Gullotta TP, Adams GR, Montemayor R, eds. Adolescent Sexuality. Newbury Park, CA: Sage; 1993:57-76.

8. Maman S, Campbell J, Sweat MD, Gielen AC. The intersections of HIV and violence: directions for future research and intervention. Soc Sci Med. 2000;50:459-478.

9. Miller BC, Monson BH, Norton MC. The effects of forced sexual intercourse on white female adolescents. Child Abuse Neg. 1995;19:1289-1301.

10. National Campaign to Prevent Teen Pregnancy. Fact Sheet on Teen Pregnancy and Childbearing Among Latinos in the United States. Washington, DC: National Campaign to Prevent Teen Pregnancy; 1999.

11. US Bureau of the Census. Population by Sex, Age, Hispanic Origin, and Race: March 2000. Available at: http://www. census.gov/population/socdemo/hispanic/p20-535/tab01-3.txt. Accessed June 3, 2003.

12. Centers for Disease Control and Prevention. HIV AIDS Surveill Rep. 2001:13(2):16.

13. Catania JA, Coates TJ, Peterson J, et al. Changes in condom use among black, Hispanic, and white heterosexuals in San Francisco: the AMEN cohort survey. J Sex Res. 1993;30:121-128.

14. Centers for Disease Control and Prevention. Youth risk behavior surveillance: US, 1997. MMWR. 1998; 47(SS-3):1-89.

15. Centers for Disease Control and Prevention. National Alternative High School Youth Risk Behavior Survey (ALT-YRBS). Available at: http://www.cdc.gov. Accessed June 3, 2003.

16. Fernandez MI. Latinas and AIDS: challenges to HIV prevention efforts. In: O'Leary A, Jemmott LS, eds. Women at Risk: Issues in the Primary Prevention of AIDS. New York, NY: Plenum; 1995:159-174.

17. Marin BV, Tschann JM, Gomez CA, Kegeles SM. Acculturation and gender differences in sexual attitudes and behaviors: Hispanic vs. non-Hispanic white unmarried adults. Am J Public Health. 1993;83:1759-1761.

18. Sabogal F, Perez-Stable EJ, Otero-Sabogal R, Hiatt RA. Gender, ethnic, and acculturation differences in sexual behavior: Hispanic and non-Hispanic white adults. Hisp J Behav Sci. 1995;17:139-159.

19. Berry JW. Acculturative stress. In: Lonner WJ, Malpass RS, 
eds. Psychology and Culture. Boston, MA: Allyn \& Bacon; 1994:211-215.

20. Marin G, Marin BV. Research With Hispanic Populations. Newbury Park, CA: Sage; 1991.

21. Aneshensel CS, Becerra RM, Fielder EP, Schuler RH. Onset of fertility-related events during adolescence: a prospective comparison of Mexican American and non-Hispanic white females. Am J Public Health. 1990;80:959-963.

22. Carmona JV, Romero GJ, Loeb TB. The impact of HIV status and acculturation on Latinas' sexual risk taking. Cultur Divers Ethnic Minor Psychol. 1999;5:209-221.

23. Darabi KF, Ortiz V. Childbearing among young Latino women in the United States. Am J Public Health. 1987;77:25-28.

24. Ford K, Norris AE. Urban Hispanic adolescents and young adults: relationship of acculturation to sexual behavior. $J$ Sex Res. 1993;30:316-323.

25. Sabogal F, Faigeles B, Catania JA. Multiple sexual partners among Hispanics in high-risk cities. Fam Plan Perspect. 1993;25:257-262.

26. Myers HF, Rodriguez N. Acculturation and physical health in racial and ethnic minorities. In: Chun KM, Organista PB, Marín $\mathrm{G}$, eds. Acculturation: Advances in Theory, Measurement, and Applied Research. Washington, DC: American Psychological Association; 2003:163-185.

27. Negy C, Woods DJ. The importance of acculturation in understanding research with Hispanic Americans. Hisp J Behav Sci. 1992;14:224-247.

28. Padilla AM. Acculturation as varieties of adaptation. In: Padilla AM, ed. Acculturation: Theory, Models, and Some New Findings. Boulder, CO: Westview; 1980:9-25.

29. Zane N, Mak W. Major approaches to the measurement of acculturation among ethnic minority populations: a content analysis and an alternative empirical strategy. In: Chun KM, Organista PB, Marín G, eds. Acculturation: Advances in Theory, Measurement, and Applied Research. Washington, DC: American Psychological Association; 2003:39-60.

30. Betancourt H, Lopez SR. The study of culture, ethnicity, and race in American psychology. Am Psychol. 1993;48:629-637.

31. Phinney JS. Ethnic socialization in adolescents and adults: review of research. Psychol Bull. 1990;108:499-514.

32. Phinney JS. The multigroup ethnic identity measure: a new scale for use with diverse groups. J Adolesc Res. 1992;7:156-176.

33. Phinney JS. Ethnic identity and acculturation. In: Chun KM, Organista PB, Marín G, eds. Acculturation: Advances in Theory, Measurement, and Applied Research. Washington, DC: American Psychological Association; 2003:63-81.

34. Hurtado A. Variations, combinations, and evolutions: Latino families in the United States. In: Zambrana RE, ed. Understanding Latino Families: Scholarship, Policy, and Practice. Newbury Park, CA: Sage; 1995:40-61.

35. Ontai LL, Raffaelli M. Ethnic identity and socialization. $J$ Adolesc Res. In press.

36. Amaro H. Considerations for prevention of HIV infection among Hispanic women. Psychol Women Q. 1988;12:429-443.

37. Ortiz V. The diversity of Latino families. In: Zambrana RE, ed. Understanding Latino Families: Scholarship, Policy, and Practice. Newbury Park, CA: Sage; 1995:18-39.

38. Rumbaut RG. Origins and destinies: immigration, race, and ethnicity in contemporary America. In: Pedraza S, Rumbaut RG, eds. Origins and Destinies: Immigration, Race, and Ethnicity in America. Belmont, CA: Wadsworth; 1996:21-42.

39. Diaz T, Buehler JW, Castro KG, Ward JW. AIDS trends among Hispanics in the United States. Am J Public Health. 1993;83:504-509.

40. Peragallo N. Latino women and AIDS risk. Public Health Nurs. 1996;13:217-222.

41. Marin G, Sabogal F, Marin BV, Otero-Sabogal R, Perez-Stable EJ. Development of a short acculturation scale for Hispanics. Hisp J Behav Sci. 1987;9:183-205.

42. Weinberg SL, Abramowitz SK. Data Analysis for the Behavioral Sciences Using SPSS. Cambridge, England: Cambridge University Press; 2002.

43. Phinney JS, Flores J. "Unpackaging” acculturation: aspects of acculturation as predictors of traditional sex role attitudes. $J$ Cross-Cult Psychol. 2002;33:320-331.

44. Espin OM. Cultural and historical influences on sexuality in Hispanic/Latin women: implications for psychotherapy. In: Espin OM, ed. Latina Realities: Essays on Healing, Migration, and Sexuality. Boulder, CO: Westview; 1987:83-96.

45. Marin BV, Gomez CA. Latino culture and sex: implications for HIV prevention. In: Garcia J, Zea M, eds. Psychological Interventions and Research With Latino Populations. Boston, MA: Allyn \& Bacon; 1997:73-93.

46. Raffaelli M, Suarez-al-Adam M. Reconsidering the HIV/AIDS prevention needs of Latino women in the United States. In: Roth NL, Fuller LK, eds. Women and AIDS: Negotiating Safer Practices, Care, and Representation. New York, NY: Haworth; 1998:7-41.

47. US Department of Commerce. We the American...Hispanics. Washington, DC: US Bureau of the Census; 1993.

48. US Dept of Health and Human Services. Mental Health: Culture, Race and Ethnicity-Supplement to Mental Health: A Report of the Surgeon General. Rockville, MD: US Dept of Health and Human Services; 2001. 
Copyright of Journal of American College Health is the property of Heldref Publications. The copyright in an individual article may be maintained by the author in certain cases. Content may not be copied or emailed to multiple sites or posted to a listserv without the copyright holder's express written permission. However, users may print, download, or email articles for individual use. 